\title{
Kitap Değerlendirmesi: Gearon, L. ve Prud'Homme, J. State Religious Education and The State of Religious Life (Eugene: Pickwick Yayınları, 2018). ISBN: 9781498287760
}

\section{Sümeyye Türkmen * (1)}

Birçok ülkede din öğretiminin devlet eğitim kurumlarında gerçekleştirilmesi, din ve devlet ilişkisini ve neticesinde oluşan karş1lıklı etkiyi gündeme getirmektedir. Dini yaşama imkânı, din eğitimi mekanizması ve din eğitiminin anayasallığı, ülkeden ülkeye söylemsel (discourse) olarak bazı farklılıklar gösterse de çoğu zaman muhafazakâr ve seküler kanadın karşı karşıya geldiği, ortak kanıya ulaşılması oldukça güç bir alan olarak karşımıza çıkmaktadır. Seküler kesim din eğitimine devlet elinin değmesini, siyasetin dindar bir bakışa sahip olmaması gerektiği ve belli dini yaklaşımların devlet yapısı içerisinde söz sahibi olmasının laiklikle bağdaşmadığı gerekçeleriyle reddederken, muhafazakâr bir kesim ise bu etkileşimi dini kaygılarla istememektedir. Muhafazakâr camianın bu kısmı devletin din eğitimine tesirinin dinin kültürüne, tarihine, toplumun din algıs1 ve pratiklerine zarar vereceği düşüncesiyle, devletin dine kaynak sağlayıcı olmadığını aksine dini tükettiğini savunmaktadır. Bu yazıda ele alınan "State Religious Education and the State of Religious Life" isimli kitap Oxford Üniversitesi'nden eğitim bilimci Liam Gearon ve Washington Üniversitesi'nden Joseph Prud'Homme tarafından yazılmıştır. Yazarlar konuları eğitim, tarih, siyaset ve din alanları çerçevesinde multidisipliner şekilde ele almakta ve ABD devlet okullarında yapılması önerilen İncil-merkezli ögrretim'i tüm zeminlerde inceleyerek öngördükleri olumsuz sonuçları temellendirmeye çalışmaktadırlar. İncil merkezli bu yaklaşım, devlet okulları için Kitab-1 Mukaddes'in tarihsel, edebî ve kültürel açılardan öğretimini hedefleyen ve temel ders kaynağı olarak Kitab-1 Mukaddesi merkeze alan seçmeli dersler önermektedir. Bu öğretimin hukuki çerçevesini, talep eden kesimin haklı yanlarını, din eğitimi üzerinde dolayısıyla dini algı ve hayat üzerinde oluşturabileceği

\footnotetext{
* Sorumlu Yazar: Sümeyye Türkmen (Öğr. Gör.), Fatih Sultan Mehmet Vakıf Üniversitesi, Yabancı Diller Bölümü, İstanbul, Türkiye. E-posta: sturkmen@fsm.edu.tr ORCID: 0000-0002-3423-1224
}

Atf: Turkmen, Sumeyye. "State Religious Education and The State of Religious Life." Liam Gearon ve Joseph Prud'Homme'un State Religious Education and The State of Religious Life adlı eserinin tanıtımı. darulfunun ilahiyat 31, 1 (2020): 185-191.

https://doi.org/10.26650/di.2020.31.1.0016 
muhtemel yan etkileri tartışan eser, problem olarak işaret edilen konulara çözüm niteliğinde farklı bir öğretim teklifi sunmaktadır.

ABD'de din-devlet ilişkilerinin temeli anayasanın İlk Tashih'in Birinci Ek Maddesidir: "Kongre ne bir dinin tesisiyle ilgili ne de bir dinin özgürce yaşanmasını yasaklayan bir kanun yapar." Ülkede seküler ve dini grupların açtığı özel okullar, devletin finanse ettiği ve farklı organizasyonlara bağlı sözleşmeli okullar, devlet okulları ve ev okulu sistem (home-schooling) mevcuttur. Tartışma konusu olan kısım, Incil-merkezli ögretim'e devlet okullarında yer verilmek istenmesidir. Çünkü devlet okulları farklı dine mensup öğrencileri bünyesinde barındırdığından, bu okulların dini dersleri öğretim programlarına eklemesinin, bahsi geçen maddeye ters düştüğü savunulmaktadır. Dini homojenliğin bulunduğu Chicago, Florida gibi eyaletlerdeki kimi devlet okullarında ise İncil ve dua okuma gibi uygulamalar tartışmalara rağmen sürmektedir. ABD her ne kadar kurumsal anlamda seküler olma çabasında olsa da, talepler karşısında din eğitimi adına farklı ve çelişkili uygulamalar yapmaktadır. Eserin yazarları bu bağlamda, Incil-merkezli öğretim'i daha geniş bir perspektifle sunmuş, kimi eyalette uygulanan kimi eyalette ise laikliğe aykırı bulunan bu yaklaşımın aslında muhafazakâr kesim için tehlike arz ettiğini rasyonel sebeplerle, tarihsel tecrübeleri de içerecek şekilde ifade etmiştir. Eserde gerekçelendirme süresince, birçok yeni kavramsallaştırma yapma gayreti gözden kaçmamaktadır. Bu açıdan eserin alan için terminoloji evreni geliştirme açısından zengin denebilecek bir içeriğe sahip olduğu söylenebilir.

Eser, çalışmanın çerçevesinin sunulduğu Giriş ve 9 bölümden oluşmuştur. İlk bölümde: "Devlet Din Eğitimi(DDE): ABD Devlet Okullarında Kitab-1 Mukaddes" başlığında yazarlar, Incil-merkezli ögrretim diğer ifadeyle Devlet Din Eğitimi (DDE) modelini, merkezine İbranice yazıtları ve Eski-Yeni Ahit metnini alan, İncil'in tarih, edebiyat ve kültüre etkisini vurgulayan ve ibadet içermeyen bir program olarak tanıtmıştır. Model ile ilgili talepler, İncil Okur-Yazarlı̆̆ı Projesi’nin $(B L P)$ oluşturduğu pedagojik model, Devlet Okullarında İncil Müfredatı Ulusal Konseyi'nin (NCBCPS) geliştirdiği müfredat ve iş adamı Steve Green'in Green Bilginler Girişimi önerisi olmak üzere 3 kategoride sunulmuştur. Son 10 yılda müfredatta İncil lehinde fazlaca talep ve işlem olmuş, bu çerçevede 10 eyalette İncil-merkezli seçmeli ders/modülün uygulanmasına dair tüzük kabul edilmiş, diğer birçok eyalet parlamentosu da talepleri değerlendirmiştir. Fakat yasalar müfredat konusunda net olmadığ için öğretim programını şekillendirme yetkisi genelde yerel eğitim kurullarına bırakılmıştır. Müfredattaki belirsizliğe karşın talep edilen seçmeli İncil dersleriyle ilgili hukuki düzenleme süreçleri devam ederken,

1 Kanunun İngilizce metni : “Congress shall make no law respecting an establishment of religion, or prohibiting the free exercise thereof.” şeklindedir. (1791) 
ülke genelinde bu derslerin sayısı çoğalmıştır. Elbette bu artış hukuki tartışmaları beraberinde getirmiştir. Seküler taraflar temelindeki dini motivasyon dolayısıyla öneriyi anti-laik ve devletin kendini koruması gereken bir talep olarak görmüştür.

"Devlet Din Dersleri ve Dini Amaç Problemi" isimli ikinci bölümde yazarlara göre seküler sol camia DDE'yi büyük ölçüde dini amaç/motivasyon taşıdığı gerekçesiyle reddetmektedir. Eleştirilerin dayandığı ortak nokta, bu derslerde Kitab-1 Mukaddes üzerinden dini etkinin artarak yaygınlık kazanması fikridir ki bu seküler ve laik devlet okulunun üstlenmemesi gereken bir misyondur. Yazarlar aynı bölümün "Eleştirilerin Merkezi ve Cevap" alt başlığında eleştirilere cevap verirken, argümanlarının merkezine anayasa teorisyeni Andras Sajo'nun iddialarını almıştır. Sajo'ya göre, kişilerin taleplerinin aksine devletin, kendisini seküler amaç dışında her türlü etkiden koruması, hatta bu konuda demokrasi militanı olması gerekmektedir (s. 21-22). Fakat demokrasiyi önemsiyor gibi görünen bu bakış, dini yaşantısını özgürce sürdürme hakkı olan kesimi görmezden gelmektedir. Yazarlar bu dışlayıcı tavrın aksine, ülke tarihinde sekülerleşmeyi sağlamış birçok dönüşümün dini hareket/amaç ile imkân bulduğunu savunmuştur. Dini talepleri sistem dışına itmek, siyaset bilimci Robert Kraynack'ın ifadesiyle ruhsal lobotomi yapmaktır (s. 24). Dini talepleri olan kişileri toplumdan kesip atan bu yaklaşım, dinin ferdi düzeyde yaşanmasını dahi baskılamak demektir. Çünkü seküler devlet okulları yerine özel dini okulları tercih eden ebeveynler, seküler devletin kabul edilebilir gördüğü programı tercih etmeyen ve yeterince iyi olmayan (less than good) vatandaşlar olarak görüleceklerdir. Yazarlar, DDE programını ABD Yüksek Mahkemesinde yakın zamanda oluşturulmuş, katı seküler yaklaşıma alternatif bir hukuki paradigma dâhilinde analize tabi tutmuştur. Yeni paradigmaya göre bahsi geçen dersler, zorunlu olmamaları sebebiyle ve dini öğretim düzenlemesinin şeffaf biçimde sürdürülmesi sonucu azınlıktaki diğer inançların kendi din derslerini talep edebilecekleri şekilde bu mekanizmaya dâhil edilmeleriyle hukuki zeminde yer bulmaktadır. Aksi takdirde hukuki taleplerde amaçların seküler olup olmadığını tespit etmek zordur ve bu süreç politik düzlemde önyargı barındırmaktadır.

Üçüncü bölümde, İncil-merkezli öğretimin rasyonel gerekçelendirmesi yapılmıştır. Talep edilen programın dini bilgileri endoktrine etmemesi durumunda, İncil'in tarihe ve kültüre etkisini öğretmenin uygun olduğu ifade edilmiştir (s. 51). İncil'in 1600 'lerden bu yana İngilizce konuşulan ülkelerde temel kaynaklardan biri olarak pedagojiye etki etmesi ve batıda çokkültürlülüğe olan vurguyla İncil merkezli yaklaşımdan uzaklaşıııış olsa da Avrupa bağlamının (discourse) İncil'le tarihsel ve kültürel ilişkisi, onun müfredattaki önemini artırmaktadır. "Kitabı Mukaddes'in Mühim Konumunu Vurgulamak" alt başlı̆̆ında, İncil'in önemine örnekler verilmektedir. İlk olarak, ABD'de kilise-devlet ayrımı (disestablishment) 
yapılırken tartışmaların çekirdeğini İncil oluşturmuştur. Öte taraftan Hıristiyan tecrübenin Amerika tarihine etki eden özgürleștirici ve iyileștirici rolü anlatılırken, İngiltere Reformasyonu'ndan başlayarak İncil'in siyasi ve toplumsal dönüşüme tesiri betimlenmiştir. Sözgelimi, ABD'de İncil'in köleliğin kaldırılmasındaki (abolition) payı tartışılmıştır. Bilim eğitiminde de İncil'in önemli olduğundan, Darwinist evrim teorisine tüm İncil yorumlarının karşı çıkmadığından, aksine İncil'in bu teoriyi destekleyen niteliğinden bahsedilmiştir. Diğer bir örnekte İncil'in toplum tabanında Marksist Sosyalizm'e karşı Social Gospel Hareketi adıyla mücadele verdiğine değinilmiştir. Toplumda Sosyal Darwinizm'in etkisini kıran bu hareket dünyalık ihtiraslardan kurtularak ihtiyaç sahiplerine yardım etmeyi amaç edinmiştir. "Baskılayıcı Sorun olarak İncil Cehaleti” alt başlığında ise Stephen Prothero'nun Din Okuryazarlığl eserinden ve 2005 Din Okuryazarlığ1 Raporu'ndan örnekler verirken artan İncil bilgisizliği kanıtlanmaya çalışılmıştır. Tüm bunlar 1şığında dersleri talep edenler nezdinde İncil'in müfredatta yer almayı hak ettiği ortaya çıkmaktadır. Burada yazarların amacı derslere olan talebin temelsiz olmadığını ortaya koymaktır lakin ileriki bölümlerde de görüleceği gibi bu dersler sunumunu yaptı̆̆ kültürü baltalamakla eşdeğer görülmektedir.

Eserin dördüncü bölümünde dinin canlılığını koruyabilmesi ve kültürel etkisini devam ettirebilmesine imkân sağlama arzusunu, politika üretici ve karar-vericilerin yasal önerilerini oluştururken dikkate alabileceği tezi tartışılmaktadır. Yazarlar bu bölüm itibariyle hukuki düzenlemeye etki edebileceğini savundukları dini saiklerden ötürü İncil-merkezli eğitimin yaygınlaşmasına karşı çıkmaktadır. Yazarlar önceki kısımlarda dersleri talep eden kesim perspektifinden bu bakış açısının haklı görülebilecek yanlarını aktarmakla esasen taleplere duyarsız kalmadıklarını göstermeye çalışmaktadır. Lakin empatik bir dil kullandıktan sonra bu bölüm itibariyle İncil derslerini talep eden kesimin aslında dikkat kesilmesi gereken noktalara yer verilmeye başlanmıştır. Şu eleştiriyi yapmak haksızlık olmayacaktır ki, bu kısımda söylemin böylesine keskin değişim göstermesi, okuyucuda ilk olarak tutarsızlık hissi uyandırmaktadır. Yazarlar bahsi geçen seçmeli derslere eleştirel yaklaştıkları sonraki kısımlarda argümanlarını derinleştirdikçe, vermek istedikleri resim daha da netlik kazanmakta ve söylemdeki değişim anlamlı hale gelmektedir. Yazarlara göre müfredat temelinde artırılmış İncil odağı, İncil'in oluşturduğu kültürel etkiyi zaman içerisinde korozyona uğratacak, bu sebeple böyle bir program dinin ontolojik durumuna olumsuz yansıyacaktır. Seküler sebepler olarak ise Bilim, Teknoloji, Mühendislik ve Matematik Eğitimi (STEM education) olarak kavramsallaşmış branşlarda yeterli kalite ve nitelikte öğretim sağlanmaması sebebiyle işverenlerin kalifiye eleman bulamadığı, Amerikalı öğrencilerin başarı sıralamasının düşük olduğu ifade edilmiştir (s. 81-82). Bu 
hususlar ise ülke refahını doğrudan etkileyen önemli eksikliklerdir. Yeni bir müfredat içeriği, ekonomik ve eğitimsel olarak yeni ihtiyaçlarla geleceğinden, sözgelimi hükümetin eğitim ödeneğinin yetersizliği, öğrenci sayısındaki artış, buna karşın K-12 öğretmenlerindeki azalma sebebiyle, İncil-merkezli öğretim eğitim mekanizmasına fazladan yük bindirecektir. Verilen sebepler, müfredatta yeni bir ders veya yaklaşımın basitçe ‘bir kesimin dini ihtiyaçlarını karşılamak’tan ziyade ekonomik, pedagojik, eğitimsel, toplumsal pek çok yansımaları olan bir süreci ifade ettiği oldukça başarılı bir şekilde gözler önüne sermektedir.

Beşinci bölümde yazarlar İncil-merkezli öğretimin İncil kültürüne olumlu değil, düşünülenin aksine menfi yansımaları olacağını 5-aşamall-argümanla açıklamaktadır (s. 85). İlk aşamada İncil, yapısal olarak bir metin olduğu için yeterli eğitimsel nitelik sağlanmadığında ezbere ve tekrara dayalı bir öğretim tehlikesi belirmektedir. Bunun sonucunda eski çağlara ait bir metne takılıp kalmış inançlı kesime karşı kültürel elitler, Hıristiyan ilahiyatçısı Albert Mohler'in deyimiyle, National Geograpic Sendromu halini alan bir tavır takınmaktadır (s. 85-86). Bu kavram muhafazakârlara karşı minik, egzotik bir kabile keşfediyormuş gibi ya da reel hayattan kopuk müzelik antika bir parçaymış (curio) gibi yaklaşımı ifade etmektedir. Ninian Smart'ın din öğretimi modeli olarak geliştirdiği, dini kendi terminoloji ve kavramları ile bir fenomen olarak ele alan eğitimsel fenomenolojik yaklaşım da İncil öğretimi açısından değerlendirilmiştir. Fakat İncil'in güzellik, İlahi yakınlık ve İlahi aşkı kabul etme zorunluluğu gibi derinlikli bir kavrayış gerektiren içeriğinin müfredatta yer alması hukuki bağlamda okulları seküler baskı altında bırakacaktır. Sonuçta, arzu edilen İncil-merkezli öğretimle okullarda Kitab-1 Mukaddes inancı ve inananları ya antika müze parçalarına dönüşecek ya da fenomenolojik yaklaşımla okullar hukuki ihtilaf hedefi ve yetersiz eğitimin verildiği kurumlar halini alacaktır. Diğer önemli bir nokta ise Amerika Din Akademisi'nin fenomenolojik yaklaşıma karşı geliştirdiği, dinin heterojen kısmına vurgu yapan yeni pedagojik yaklaşımdır. Bu alternatif pedagoji, dinin tek anlamlı ve değişmez düsturlarını sunmaksızın, din hakkında bilgisi olmayan öğrencileri, dinin en ücra köşesindeki farklılığı bilen kimseler haline getirmekte fakat temel kaidelerin bilgisini vermediği için bir başka problem alanı ortaya çıkmaktadır.

Yazarlar altıncı bölümde, radikal İslamcı söyleme karşı, devletin hakiki İslam'ın tanımını kabul ettiğini ve bu tanıma uyan inanışı teminat altına aldığını ifade etmiştir (s. 112). İslam'ın Amerika ve Batı ülkelerinde 1lımlı İslam yaklaşımıyla başına gelenler tabiri caizse ibretlik bir durum olarak İncil derslerini talep edenleri uyarmak adına sunulmuştur. İncil-merkezli öğretimle bu defa devlet, belirlediği tanıma uyan Hıristiyanlık formunu aktararak devlet eğitimini teminat altına alacaktır (securitization). Böylece devlet, siyasi konjonktüre uygun, politik aktörlere sorun 
çıkarmayan, 1lımlı, çoğulcu, senkretik, dünya dinleri alaşımı olan bir dini sunuma başvurabilecektir.

Yedinci bölümde yazarlar, yukarıda bahsi geçen çoğulcu yaklaşım dâhil olmak üzere İncil-merkezli eğitimin kaygı verici birçok diğer durumunu, İngiltere'nin kronolojik din eğitimi tecrübesi üzerinden açılamaktadırlar. İngiltere din eğitimi tarihi Hıristiyan Britanya'nın ölümüdür (s. 121). Çünkü tarihsel süreçte artan din dersleri niteliksel düşüşe ve günümüz İngiltere'sinde pasif bir dini duruş ve düşünüşe sebebiyet vermiştir.

İngiltere kesitinde yaptığı incelemeyi sonraki bölümde genişleten eser, Avrupa kıtasında devlet din eğitimi etkilerini, REDCo Projesi (REDCo Project) araştırma verileri çerçevesinde ele almıştır. Bu bölümde yazarlar Avrupalı Sivil Din'in yani politize olmuş sekülerizmin izin verdiği oranda varlığını sürdüren ve çoğulcu olan din kavramının, beklenen dini marjinalleşmenin aksine sekülerleşmeyi sağlayacak şekilde eğitim vasıtasıyla yaygınlaştı̆̆ı sonucuna varmıştır. Yazarlara göre Avrupa'da Tanrı'nın dönüşü dini değil politik bir geri dönüştür ve din eğitimindeki artışla çoğulculuğa (pluralism) dayalı din öğretiminin ortaya çıkışı pedagojik bir zorunluluk ve politik bir zaruriyettir. Oysa bireylerin aslî dini duyarlılıklarındaki gevşemenin temelinde bu sivil din yatmaktadır. Zira çoğulculuk bağlamında oluşmuş eklektik dini yaklaşım vasıtasıyla, yaşantıya dönüşmesi beklenen din, genel kültür ve tarih bilgisine hapsolmakta, dini tecrübe ve dinin yaşamla bağı yok olmaktadır.

Dokuzuncu ve son kısmında Güney Carolina'da oluşturulmuş, yazarlara göre olumlu fakat araştırılması gereken serbest zaman sistemi (Release Time System) sunulmaktadır. Yazarlar bununla, okul kampüsü dışında, öğretim müfredatı ve yeterliliğe sahip öğretim elemanı bulunması gibi kriterlere sahip özel okul ve/ veya kurumlarda verilen seçmeli İncil derslerini kastetmektedir. Böylece devlet kurumunda sıradanlaşmayacak İncil öğretimi, özel okulun maddi kaynaklarından faydalanacak, devlet eğitim mekanizmasına yük olmayacaktır (s. 155-158). Ancak bahsedilen sistemde derslerin özel kurumlarda ücretli olup olmadığı net değildir. Paralı olması durumunda dersleri talep eden ailelerin ücreti ödeyecek mali durumda olması gereklidir. Ödeneğin devlet tarafından sağlanması ise radikal seküler taraflar açısından tartışma konusu olacaktır.

Her ne kadar asıl amaçları yeni bir yaklaşım veya müfredat sunmak olmasa da, argümanlarıyla vardıkları son noktada yazarların çerçevesini netleştirdiği makul bir sistem geliştirmesi arzu edilebilir gözükmektedir. Böylelikle eleştirilen sisteme karşın olması gereken düzeni daha net sunmak, eserin kapsamını ve vizyonunu geliştirecektir. 
Eser, din öğretimine devlet müdahalesini İncil öğretimi üzerinden ABD özelinde değerlendirse de din eğitimi alanına ilgi duyan ve bu alanda çalışmalarını yürüten okuyucu kitlesine derin ve geniş çaplı perspektif sunması açısından oldukça kıymetlidir. Yalnızca ABD'de değil, küresel ölçekte din öğretiminde nicelik arttıkça, niteliksel düşüş yaşanma tehlikesi baş göstermektedir. Din öğretimi hukuki zeminde yer bulurken, İncil veya başka bir kutsal metin merkezli derslerin devlet okullarında yaygınlık kazanması yalnızca maddi anlamda zorluklar taşımamaktadır. Kutsal metinler ders kitabı halini aldığında derinliğinin, saygınlığının kaybolmasının ve seküler camianın eleştiri oklarına maruz kalmasının önü açılmaktadır. Yazarlar karşı çıktıkları DDE'yi objektif biçimde ele almaya çalışmış, olumlu yanlarını ve temelinde yatan motivasyonları sunarak konunun farklı boyutlarını ortaya koymuşlardır. Lakin eser sunduğu alternatif öğretim modeli açısından yeterli eğitimsel sistematiği geliştirmemektedir. Bu açıdan daha çok var olan ve artış gösteren din öğretimi durumunu analiz eden ve eleştiren bir eser özelliği taşımaktadır. Eser muhafazakâr kanat ve din eğitimcilerinin yasal olarak din öğretimi adına yaptıkları taleplerin maddi, manevi, kültürel, tarihsel, yerel, küresel ve siyasi açılardan geçmişini, bugününü ve gelecekte oluşabilecek olumlu-olumsuz muhtemel sonuçlarını içeren bir vizyon dâhilinde değerlendirilmesi gerektiğini hatırlatan bir kaynak niteliğindedir. 
